\title{
Applying Sustainable Development to Economic Challenges of Small and Medium Enterprises after Implementation of Targeted Subsidies in Iran
}

\author{
Rouhollah Sohrabi (D, ${ }^{1}$ Koorosh Pouri, ${ }^{2}$ Majid Sabk Ara, ${ }^{3}$ \\ Sayyed Mohammadreza Davoodi, ${ }^{4}$ Esmaeel Afzoon, ${ }^{5}$ and Adel Pourghader Chobar $\mathbb{C}^{6}$ \\ ${ }^{1}$ Faculty of Economics and Social Sciences, Bu-Ali Sina University, Hamedan, Iran \\ ${ }^{2}$ Department of MBA, University of Science and Technology, Tehran, Iran \\ ${ }^{3}$ Faculty Member in Guilan ACECR, Educational Member in Guilan UAST, Tehran, Guilan, Iran \\ ${ }^{4}$ Department of Management, Dehaghan Branch, Islamic Azad University, Dehaghan, Iran \\ ${ }^{5}$ Department of Theoretical Economics, Faculty of Economics, Allameh Tabatabaei University, Tehran, Iran \\ ${ }^{6}$ Department of Industrial Engineering, Faculty of Industrial and Mechanical Engineering, Qazvin Branch, \\ Islamic Azad University, Qazvin, Iran
}

Correspondence should be addressed to Rouhollah Sohrabi; r.sohrabi@basu.ac.ir

Received 29 August 2021; Revised 15 October 2021; Accepted 9 November 2021; Published 25 November 2021

Academic Editor: Alireza Goli

Copyright (c) 2021 Rouhollah Sohrabi et al. This is an open access article distributed under the Creative Commons Attribution License, which permits unrestricted use, distribution, and reproduction in any medium, provided the original work is properly cited.

\begin{abstract}
Although small and medium enterprises are important in the production and employment, these firms have structural limitation in terms of human and material resources. These limitations are highlighted after implementation of targeted subsidies in Iran, release prices of energy carriers, and simultaneity of political and economic situation. The main challenge in the current path of sustainable development is addressed to all sectors of society such as engineering and production. Manufactured products must consider the impact of three aspects of sustainability over their life cycle. The three aspects of sustainability as an integral part of sustainability issues are economic, environmental, and social factors. Therefore, in this study, for achieve sustainable economic development in Iran, consider only economic aspect. Because, it will greatly benefit from the transfer of advanced production technologies in industry through international agreements such as the clean development mechanism (CDM). However, the highly competitive environment is critical because of more cost-effective projects, which is why Iran needs to strike a balance between sustainable development and profitability for projects. In this study, identifying and ranking of major challenges of leading small and medium industries have been studied. It also uses the failures mode and effect analysis (FMEA) technique and survey experts and managers of small and medium industries in the province recognized and decision model using several branches. VIKOR was ranked as the most important challenge. The results show that exchange rate volatility has been the highest priority, so the first challenge has been identified. Similarly, the political boycott and the rise in the cost of production and cost of product manufacturing enterprises were identified as the next challenges.
\end{abstract}

\section{Introduction}

Today, small and medium enterprises are considered as major factors in the growth of the industrial structure of the country, and they are very important in a lot of developing countries' industries that sought to revive their economic structure. These countries have understood that in order to speed up the process of industrialization, priority should be given to the development of small and medium industries and not big industries. For this reason, we have an unprecedented enthusiasm of the small industries in many different countries [1]. The most important advantages that make economic policies to focus on small and medium industries are as follows: first, training of capable managers 
in the competitive environment [2]; second, making an effective role in entrepreneurship and job creation, resulting in increased exports and high functionality, and at the same time, adapting to the policies of downsizing, outsourcing, and reengineering [3]. Developing has been futile $[4,5]$. In our country, in despite of the huge number of small industries, there are failures in their industrial structures, as they are not able to do effective roles as small industries in developed and developing countries. [4-6]. High cost of production in Iran, the weakness of the banking system, problems in taxation and customs issues, and inadequate financial support are things that undermine these firms, decline production, and take them of the production system [4].

The law of subsidies is one of the most important components of the economic development plan that has significant impacts on the industrial sector. Hence, this study aims to identify the main challenges that concerns recognizing challenges of subsidy for small and medium-sized manufacturing enterprises in relation to the development of their activity. The article focuses on subsidy and economic firms and 30 important challenges and their priorities that firm encounter. In the last part, the major findings and recommendations are presented.

Therefore, main contributions of this study are as follows:

(i) Identify the challenges facing industries after government subsidies

(ii) Ranking and determining the most important challenge facing industries after government subsidies using multiple criteria decision making (MCDM)

The rest of this study is organized as follows. In Section 2, basic issues such as the concept of subsidies, types of subsidies, subsidy goals, sustainable development literature review, and motivation and contribution are presented. In Section 3, methodology and the VIKOR decision-making method are explained. In Section 4, the results are presented. In Section 5, the managerial insights and main limitations of the research are presented, and finally, in Section 6, an overall conclusion is presented.

\section{Literature Review}

In this section, the impact of successful implementation of targeted government subsidies for sustainable development is reviewed. Sustainable development can be defined as the practice of maintaining the productivity by replacing resources used with resources of equal or greater value without degrading or endangering natural biotic systems [7]. Sustainable development binds together concern for the carrying capacity of natural systems with the social, political, and economic challenges faced by humanity. Sustainability science is the study of the concepts of sustainable development and environmental science. There is an additional focus on the present generations' responsibility to regenerate, maintain, and improve planetary resources for use by future generations $[8,9]$. For this purpose, Liu et al. [10] presented the evolutionary dynamics in China's electric vehicle industry for taxes and subsidies. In this study, the production fluctuation in electric vehicle (EV) industry is explained by evolutionary game. The optimal decision of two players and Nash equilibrium is derived in three decision scenarios. Also, the influence of government intervening in consumer demand and vehicle supply on EV industry development path is examined. Finally, results show that the policy of dynamic emission taxations and static subsidies is more effective in the EV industry development. Kumar et al. [11] evaluated the effectiveness of fisheries subsidies as a trade policy tool to achieving sustainable development goals at the WTO. To this end, this study provides possible implications of the fisheries subsidies as a trade policy tool for market access and its effectiveness in achieving the overall sustainable development goals. To examine the effectiveness of subsidies in fisheries negotiations, the study focuses on the global supply and demand side of the fisheries resources from the perspective of the fish resource holders and the fishing resource capacity. Using both the market demand and supply for fisheries resource extraction, the study examines the effectiveness of subsidies as a trade policy tool to attain the overall sustainable development goals. Based on the analysis, certain policy strategies follow, which are important for countries to consider before the elimination of fisheries subsidies at the WTO. Moghaddam and Wirl [12] determined the oil price subsidies in oil and gas exporting countries. According to the political policy, it is easy to grant subsidies but much more difficult to remove them. High oil revenues tend to raise subsidies and make abolishing them more difficult. Therefore, without proper policies, domestic demand will explode. Grilli and Murtinu [13] considered selective subsidies, entrepreneurial founders' human capital, and access to R\&D alliances. Because, selective subsidies help new technology-based firms (NTBFs) access R\&D alliances and also apply both R\&D alliances with other firms and R\&D alliances with public research organizations/universities. Founders' technical education is a key determinant for NTBFs to get the first selective subsidy. Findings show that founders' previous industry-specific work experience positively moderates the impact of subsidies on the likelihood to form a corporate R\&D alliance. Thorne and Hughes [14] evaluated the effectiveness of electric vehicle subsidies in Canada. In this study, the cost-effectiveness of achieving emissions reductions through $\mathrm{EV}$ subsidy programs is evaluated with respect to each provincial electricity system in Canada. These results were then used to compare the costefficiency of EV subsidies to other investments in climate change mitigation initiatives, and ultimately decide whether EV subsidies are feasible to implement in any of Canada's provinces. Solarin [15] examined the factors affecting energy intensity to sustainable development and its components such as electricity intensity, oil intensity, gas intensity, and coal intensity. In this study, special attention is paid to the roles of the fossil fuel subsidies, which include total fossil fuel, fossil-fueled electricity, oil, gas, and coal subsidies in developing countries. Using a generalized method of moments approach, it is shown that increase in fossil fuel, electricity, oil, gas, and coal subsidies promote energy 
intensity or its component elements. The results further suggest that urbanization, industrialization, and foreign direct investment also promote energy intensity. Also, it is noted that real gross domestic product per capita and human capital development have negative impact on energy intensity and its components. Moreover, the countries are clustered according to their income level, and the relationship in the variables is reexamined in each of the clusters. The results are not substantially different to those obtained for the total sample. The implications of these empirical findings are analyzed in the study. The priority development of public transport cannot be achieved without the support of the government's fiscal and taxation policies, while the implementation of the subsidy policy is the joint effect of multiple stakeholders. For this purpose, Zhang et al. [16] analyzed the implementation mechanism of public transport subsidy policy from the perspective of carbon emission to discuss the evolutionary stability strategy of tripartite game under different situations, thereby, clarifying the key factors affecting the evolutionary path of the stability strategy through simulation. The main conclusions achieved are as follows. (1) When the subsidy and sunk cost are greater than the improper profit brought by the false report and the travel cost (time and economy) of public transport is greater than that of the individual motorized travel combined, the three will eventually arrive at the state in which government chooses no-audit, the enterprise chooses true report, and the resident choose public transport. (2) More government supervision can help reduce the false reporting behavior of public transport enterprises in the implementation of public transport subsidy policy. (3) The punishment and the improper profit brought by the false report are also the key factors that influence the behavior decision-making of the government and the enterprises. (4) The economic cost of travel plays an important role in the evolution path of residents' stabilization strategy, yet is of little significance on the behavior decision of enterprises and governments. From the perspective of sustainable transportation development, it is necessary for the government to control or even reduce the ticket price of public transport and to increase the economic cost of individual motorized travel. Increased stress on environmental pollution, resource consumption, and public health resulting from the rapid growth of kitchen waste (KW) necessitated a disposal way of recycling and reuse. Therefore, Shi et al. [17], in their study, considered three disposal lines to convert KW into clean and renewable energy products, during which a Stackelberg equilibrium-based model is developed to achieve a balance between cost savings, carbon emissions reduction, and profit making by considering the interests of the local government and KW disposal plants. Recently, the outbreak of the COVID-19 pandemic poses great challenges to the current government subsidy models in the renewable energy sector for recovering in the postpandemic economy. Although, many subsidy models have been applied to accelerate renewable energy investment decisions. However, it is important to develop a new model to ensure the sustainability of the renewable energy supply network under disruptions on both the supply and demand sides due to hazardous events. For this purpose, Tsao et al. [18], in their study, investigated different subsidy models (renewable credit, supplier subsidy, and retailer subsidy) to find a win-win subsidy model for sustainable energy supply under disruption risks. The objective is to determine the optimal capacity of renewable energy added to the grid, the optimal wholesale price of the power plant, and the optimal retail price of the aggregator under different subsidy models to maximize the economic, social, and environmental benefits of the whole network. A novel scenario-based robust fuzzy optimization approach is proposed to capture the uncertainties of business-as-usual operations (e.g., some relevant costs and demand) and hazardous events (e.g., COVID-19 pandemic). The proposed model is tested in a case study of the Vietnamese energy market. The results show that for a high negative impact level of hazardous events on the supply side, the renewable credit and supplier subsidy models should be considered to recover the renewable energy market. Furthermore, the proposed approach has a better performance in improving the power plant's robust profit for most of the hazard scenarios than the robust optimization model. Song et al. [19] evaluated the effects of government subsidies on the sustainable innovation of university-industry collaboration. This research shows that members in the universityindustry collaboration who receive the government subsidy will produce more profit and also concluded that the government subsidy rate is negatively related to the consumer demand impact coefficient. Therefore, with the same level of effort, enterprises receiving government subsidies will generate greater social welfare. Finally, these study results can help governments to define sustainable innovation subsidy policy. Table 1 provides the research literature by the method, industry, and considered characteristics.

2.1. Motivation and Contribution. According to the abovementioned, studies have generally focused on identifying economic challenges and their impact on subsidies in each industry. Based on the knowledge gained, there are few studies that pay attention to both identification and ranking challenges. Therefore, the valuable contributions of this study are as follows:

(i) Identify the challenges facing industries after government subsidies

(ii) Ranking and determining the most important challenge facing industries after government subsidies

Based on main contribution of this study abovementioned, the main research questions are as follows:

(i) What are the main challenges facing small and medium enterprises after the implementation of targeted subsidies from an economic perspective? 
TABLE 1: Literature categorized.

\begin{tabular}{|c|c|c|c|c|}
\hline Author & Year & Method & Industry & Attribute \\
\hline Liu et al. & 2017 & Evolutionary dynamics game & Electric vehicle & $\begin{array}{l}\text { (i) Government intervening in consumer } \\
\text { demand } \\
\text { (ii) Vehicle supply }\end{array}$ \\
\hline Kumar et al. & 2018 & $\begin{array}{c}\text { Evaluated effectiveness of } \\
\text { fisheries } \\
\text { subsidies }\end{array}$ & Fisheries subsidies & $\begin{array}{l}\text { (i) Global supply } \\
\text { (ii) Demand side of fisher }\end{array}$ \\
\hline $\begin{array}{l}\text { Moghaddam and } \\
\text { Wirl }\end{array}$ & 2018 & Determined oil price subsidies & Oil and gas & $\begin{array}{l}\text { (i) Oil revenue } \\
\text { (ii) Domestic demand }\end{array}$ \\
\hline Thone and Hughes & 2019 & $\begin{array}{c}\text { Evaluate effectiveness of electric } \\
\text { vehicles }\end{array}$ & Electric vehicle & (i) Cost-effectiveness \\
\hline Tsao et al. & 2020 & $\begin{array}{l}\text { Investigated different subsidy } \\
\text { models }\end{array}$ & Energy & $\begin{array}{l}\text { (i) Renewable credit } \\
\text { (ii) Supplier subsidy } \\
\text { (iii) Retailer subsidy }\end{array}$ \\
\hline Song et al. & 2022 & Evaluated government subsidies & University-industry & (i) Consumer demand \\
\hline This study & $\begin{array}{l}\text { Current } \\
\text { year }\end{array}$ & $\begin{array}{l}\text { Identifying and ranking using } \\
\text { MCDM }\end{array}$ & $\begin{array}{l}\text { Small and medium } \\
\text { industries }\end{array}$ & $\begin{array}{l}\text { (i) Possibility to happen } \\
\text { (ii) Amount of risk } \\
\text { (iii) Possibility to control }\end{array}$ \\
\hline
\end{tabular}

(ii) What are the priorities the small and medium enterprises subsidies challenges?

\section{Methodology}

Figure 1 shows the proposed framework of the research. This study is a descriptive and exploratory research based on surveys of experts. It is an applied research and uses the descriptive study, with the data field of the library from two ways: (i) libraries (search, study, and use of documents, texts, magazines, and newspapers economy) and (ii) other than libraries (preliminary interviews and questionnaires) to extract the indicators of population, and then with surveys of experts and specialists authorities, it weighs and ranks the challenges done. To do the research, a list of experts has been made to conduct research in Hamedan province with the help of industrial estates in connection with managers of government agencies and the private sector on the other hand. Totally, 25 experts declared their readiness to respond to the questionnaire. Most of the questionnaires have been spread among managers and experts who are fully informed about problems of production in Hamedan (in Iran) and who were aware of policies in the field or who were the supervisors or executors of governmental plans. The experts enjoy the following major features:

(i) They have no formal training and were less than undergraduate level, so half of them had bachelor, other half at the graduate level, and one at the $\mathrm{PhD}$ level.

(ii) People in the group of measuring the value had at least 14 years' experience in different and associated fields. So in one hand, they were informed about documents, rules, and policies of states in the field of production, and on the other hand, they were related to the managers of production companies, and sometimes, they had some collaboration and management in production.

(iii) Having diversity of work experience in various fields

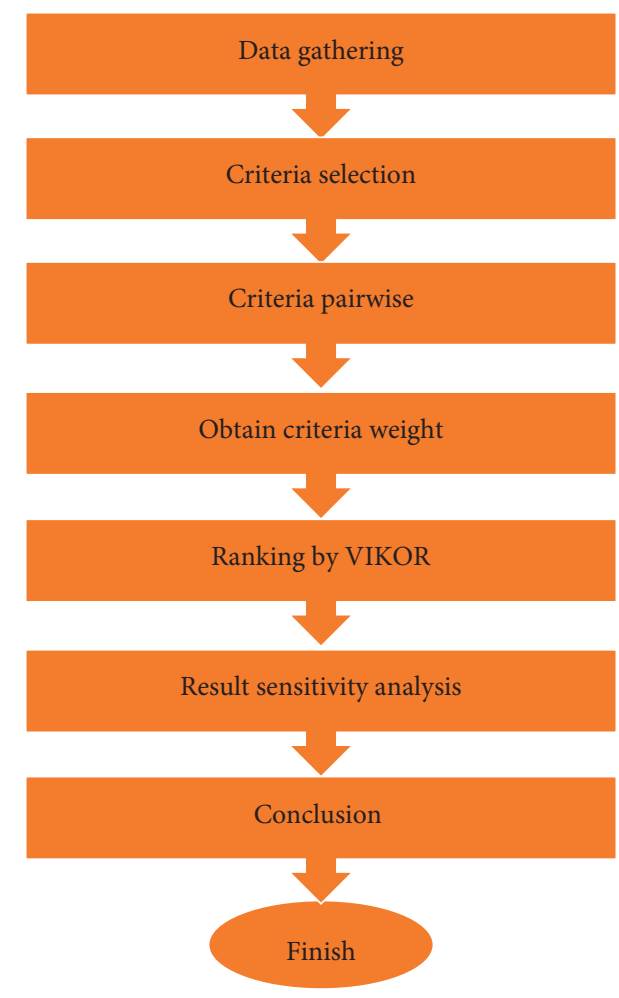

Figure 1: Proposed research framework.

The method used in this research is VIKOR. VIKOR, a compromised MADM method, was developed in 1998 based on LPG. This multicriteria decision-making method is created for solving a discrete decision problem with disproportionate measures (different measurement units). This method focuses on ranking and selecting an alternative category and determines compatible solutions to the problem even with conflicting criteria. It can help decision makers to reach to a final decision. Compliant solution is a feasible solution that is the closest to the ideal solution. Compatibility means the answer which is made by the 
mutual compromise. VIKOR advantages can be mentioned as follows:

(i) Necessarily, in the model, we do not require using expert' opinions to evaluate options based on criteria, and we can use raw data. For example, in the criteria of "connection way" to evaluate which village has a suitable condition, we can measure the connection way to the village and put it in the model, without using the experts' opinion. This evaluation can be based on raw data or based on expert opinion. The aim of this model is to determine the weight and value of each option and rank them. There is no need to complex software, and considering that in all the parts, the mathematical formulas have been used, and we can use Excel software to realize the goal [20].

(ii) The VIKOR method uses linear normalization and the TOPSIS method uses vector normalization. In VIKOR method, the normalized amount does not depend on the criteria measure unit. However, in the TOPSIS method, the normalized amount depends on the criteria measure unit.

To evaluate the risk in most of the resources, only two criteria, "probability" and "effect" of risk, have been used, while some other resources use "risk control criteria" or "eliminate risk criteria." In this study, all three criteria are considered for ranking the challenges as risks. There are several methods for risk assessment, including FMEA (failure modes analysis and its effects), FMECA (analysis of critical scenarios and consequences of it), HAZOP (analysis of the associated risks with the process), and FTA (tree hazard analysis). But the most valid method is FMEA which is first used by America's military to decrease the risk management as well as the risks of natural disasters' damages [21]. This method is used to predict and prevent errors [22]. The prediction is done by experts who have enough knowledge and experience about the design process or service. According to [23], the advantages of this method are as follows:

(i) Assessing the current situation (possible risk control)

(ii) A more accurate and realistic risk assessment methods than the traditional methods

(iii) A reliable method for predicting risk and managing preventive solutions

3.1. VIKOR Method. The VIKOR is a method developed by Opricovic in 1998. It is based on the definition of the vector of weights for the established criteria based on expert knowledge [24]. This approach obtains in the next steps, after certain transformations, the closeness of the solution to the ideal solution. Based on this distance, the final ranking is determined, assessing the quality of the alternatives tested. The result obtained may largely depend on the weights for the criteria defined at the beginning [25]. The vector of the weights specified by the expert should meet the following condition:

$$
\sum_{i=1}^{N} w_{i}=1
$$

Each of the criteria is initially defined as a cost or profit type of criteria (2). The cost type shows that we want it to achieve the lowest possible values, while the profit type should achieve the highest possible values.

$$
\begin{gathered}
f_{i}^{*}=\max _{j} f_{i j}, f_{i}^{-}=\min _{j} f_{i j}, \quad \text { if } i^{\text {th }} \text { criterion is the profit, } \\
f_{i}^{*}=\min _{i} f_{i j}, f_{i}^{-}=\max _{j} f_{i j}, \quad \text { if } i^{\text {th }} \text { criterion is the cost, } \\
w_{j} \cdot \frac{f_{j}^{*}-f_{i j}}{f_{j}^{*}-f_{i}^{-}}
\end{gathered}
$$

For each of the criteria, the best $f_{i}^{*}$ and the worst $f_{i}^{*}$ values are defined. Then, using equation (3), preference values for each criterion are calculated, taking into account the weights for criteria defined at the beginning. On this basis, the closeness to the ideal solution is calculated, considered in three different rankings calculated from the following formulas (4)-(6) for $S, R$, and $Q$, respectively.

$$
\begin{aligned}
S_{i} & =\sum_{j=1}^{N} w_{j} \cdot \frac{f_{j}^{*}-f_{i j}}{f_{j}^{*}-f_{i}^{-}}, \\
R_{i} & =\max _{j}\left[w_{j} \cdot \frac{f_{j}^{*}-f_{i j}}{f_{j}^{*}-f_{i}^{-}}\right], \\
Q_{i} & =v \cdot \frac{s_{i}-s^{*}}{s^{-}-s^{*}}+(1-v) \cdot \frac{R_{i}-R^{*}}{R^{-}-R^{*}} .
\end{aligned}
$$

The VIKOR method is useful, especially in situations when a decision maker cannot express his/her preference. Even if the achieved ranking is not as accurate as the decision maker expects it to be, the weights for each criterion could be redefined. All processes could be performed once more to check if the obtained results are closer to the expected ranking. Moreover, this method provides results that depend on the ideal solution, which stands only for the given set of alternatives. It means that changing the group of alternatives and their values for specified criteria would affect receiving an utterly new preference ranking in which position for each option can differ in comparison with the one received in the previous attempt.

3.2. Criteria Identifying. In this study, three criteria are considered for ranking choices. All three criteria are selected from literature, as given in Table 2 . 
TABle 2: Criteria selection.

\begin{tabular}{lc}
\hline Criteria & Resource \\
\hline Possibility to happen & Izadyar and Pride [20]; Ghasemi [5]; Dicle and Dicle [26] \\
Amount of risk & Cant et al. [27]; Lin and Zhang [28] \\
Possibility to control & Zoogah et al. [29]; Solarin [15]; Zhang et al. [16] \\
\hline
\end{tabular}

Table 3: Pairwise, normalized, and criteria weight.

\begin{tabular}{lccc}
\hline Pairwise & Possibility to happen & Amount of risk & Possibility to control \\
\hline Possibility to happen & 1 & 3 & 5 \\
Amount of risk & 0.33 & 1 & 5 \\
Possibility to control & 0.20 & 0.20 & 1 \\
\hline Normalized & Possibility to happen & Amount of risk & Possibility to control \\
Possibility to happen & 0.65 & 0.71 & 0.45 \\
Amount of risk & 0.21 & 0.24 & 0.45 \\
Possibility to control & 0.13 & 0.05 & 0.10 \\
Weight & 0.60 & 0.30 & 0.10 \\
\hline
\end{tabular}

Table 4: Decision matrix.

\begin{tabular}{|c|c|c|c|c|}
\hline & Criteria & $\begin{array}{c}\text { Possibility to } \\
\text { happen }\end{array}$ & $\begin{array}{l}\text { Amount of } \\
\text { risk }\end{array}$ & $\begin{array}{c}\text { Possibility to } \\
\text { control }\end{array}$ \\
\hline \multirow{33}{*}{ Choices } & Criteria's weight & 0.60 & 0.30 & 0.09 \\
\hline & Lack of liquidity & 6 & 5.92 & 5.62 \\
\hline & High production costs & 7.23 & 6.92 & 6.31 \\
\hline & Reduced profit margins & 6.31 & 5.92 & 6.46 \\
\hline & Low quality of national production & 4.54 & 5.77 & 5.15 \\
\hline & Lack of innovation and creativity atmosphere & 4.92 & 6.15 & 4.54 \\
\hline & Prolongation of profitability & 5.15 & 6.31 & 5.54 \\
\hline & Lack of agility in operations & 4.46 & 5.62 & 5.62 \\
\hline & Lack of the marketing mechanism & 5.85 & 6.38 & 5.15 \\
\hline & Unfavorable business atmosphere & 5.69 & 6.54 & 5.08 \\
\hline & Lack of information and knowledge & 4.38 & 6.08 & 5.15 \\
\hline & Existence of insecure investment environment & 6.15 & 6.46 & 6.15 \\
\hline & Inflation & 7.15 & 6.23 & 6.62 \\
\hline & Economic downturn & 5.62 & 5.77 & 6.38 \\
\hline & Price gap & 6.38 & 6.08 & 6.15 \\
\hline & Growing instability & 6.77 & 6.46 & 6.00 \\
\hline & Rising energy prices & 6.23 & 5.92 & 6.31 \\
\hline & Unpredictability of economic variables & 5.92 & 5.77 & 5.92 \\
\hline & Lack of local buyers & 4.92 & 5.23 & 5.54 \\
\hline & Lack of implementation of the government's commitment in the support package & 6.23 & 5.69 & 6.69 \\
\hline & Lack of coordination between the financial institutions and the executive & 5.77 & 5.92 & 6.00 \\
\hline & Existence of exclusive production firms & 4.00 & 5.00 & 6.15 \\
\hline & Lack of cooperatives & 4.62 & 5.00 & 5.92 \\
\hline & The lack of a systematic strategy & 6.23 & 6.00 & 5.85 \\
\hline & Diversity policies & 6.31 & 6.31 & 5.62 \\
\hline & Cumbersome rules & 5.69 & 6.69 & 6.00 \\
\hline & Payment with high profit & 5.46 & 6.31 & 5.85 \\
\hline & Dependence on foreign technology & 5.08 & 6.15 & 6.00 \\
\hline & Lack of classified and frequent monitoring & 6.69 & 6.92 & 6.46 \\
\hline & Political sanctions & 7.00 & 7.08 & 6.62 \\
\hline & Exchange rate volatility & 7.23 & 7.62 & 6.69 \\
\hline & $f_{i}^{*}$ & 7.23 & 7.62 & 6.69 \\
\hline & $f_{j}^{*}$ & 4.00 & 5.00 & 4.54 \\
\hline
\end{tabular}


TABLE 5: Calculation of $S_{i}$ value.

\begin{tabular}{|c|c|c|c|c|}
\hline & Criteria & $\begin{array}{c}\text { Possibility to } \\
\text { happen }\end{array}$ & $\begin{array}{l}\text { Amount of } \\
\text { risk }\end{array}$ & $\begin{array}{c}\text { Possibility to } \\
\text { control }\end{array}$ \\
\hline \multirow{32}{*}{ Choices } & Lack of liquidity & 0.23 & 0.11 & 0.04 \\
\hline & High production costs & 0.00 & 0.22 & 0.02 \\
\hline & Reduced profit margins & 0.17 & 0.11 & 0.01 \\
\hline & Low quality of national production & 0.50 & 0.09 & 0.06 \\
\hline & Lack of innovation and creativity atmosphere & 0.43 & 0.13 & 0.09 \\
\hline & Prolongation of profitability & 0.39 & 0.15 & 0.05 \\
\hline & Lack of agility in operations & 0.51 & 0.07 & 0.04 \\
\hline & Lack of the marketing mechanism & 0.26 & 0.16 & 0.06 \\
\hline & Unfavorable business atmosphere & 0.29 & 0.18 & 0.07 \\
\hline & Lack of information and knowledge & 0.53 & 0.12 & 0.06 \\
\hline & Existence of insecure investment environment & 0.20 & 0.17 & 0.02 \\
\hline & Inflation & 0.01 & 0.14 & 0.00 \\
\hline & Economic downturn & 0.30 & 0.09 & 0.01 \\
\hline & Price gap & 0.16 & 0.12 & 0.02 \\
\hline & Growing instability & 0.09 & 0.17 & 0.03 \\
\hline & Rising energy prices & 0.19 & 0.11 & 0.02 \\
\hline & Unpredictability of economic variables & 0.24 & 0.09 & 0.03 \\
\hline & Lack of local buyers & 0.43 & 0.03 & 0.05 \\
\hline & Lack of implementation of the government's commitment in the support package & 0.19 & 0.08 & 0.00 \\
\hline & Lack of coordination between the financial institutions and the executive & 0.27 & 0.11 & 0.03 \\
\hline & Existence of exclusive production firms & 0.60 & 0.00 & 0.02 \\
\hline & Lack of cooperatives & 0.48 & 0.00 & 0.03 \\
\hline & The lack of a systematic strategy & 0.19 & 0.11 & 0.04 \\
\hline & Diversity policies & 0.17 & 0.15 & 0.04 \\
\hline & Cumbersome rules & 0.29 & 0.19 & 0.03 \\
\hline & Payment with high profit & 0.33 & 0.15 & 0.04 \\
\hline & Dependence on foreign technology & 0.40 & 0.13 & 0.03 \\
\hline & Lack of classified and frequent monitoring & 0.10 & 0.22 & 0.01 \\
\hline & Political sanctions & 0.04 & 0.24 & 0.00 \\
\hline & Exchange rate volatility & 0.00 & 0.30 & 0.00 \\
\hline & $S_{i}$ & 7.97 & 3.92 & 0.97 \\
\hline & $R_{i}$ & & 7.97 & \\
\hline
\end{tabular}

TABLE 6: VIKOR index value and ranking.

\begin{tabular}{lccc}
\hline Criteria & $\begin{array}{c}\text { Possibility to } \\
\text { happen }\end{array}$ & Amount of risk & Possibility to control \\
\hline$Q$ & 0.873 & 0.958 & 0.071 \\
Rank & 2 & 1 & 3 \\
\hline
\end{tabular}

\section{Results}

The data were collected from questionnaires; first, we calculate the weight of normalized criteria through arithmetic mean. Table 3 provides the pairwise, normalized, and weight of the criteria, possibility to happen, amount of risk, and possibility to control. According to Table 3, the normalized values are between zero and one, and the sum of the weights obtained is equal to one. Second, the decision matrix is given in Table 4. Also, the results of the calculations made to VIKOR are given in Table 4; then, the challenges in order of priority of importance criteria are determined.

According to Table 4 , value of $f_{i}^{*}$ and $f_{j}^{*}$ is calculated. Use $f_{i}^{*}$ and $f_{j}^{*}$ based on the VIKOR method $w_{j} \cdot\left(\left(f_{j}^{*}-\right.\right.$ $\left.\left.f_{i j}\right) /\left(f_{j}^{*}-f_{i}^{-}\right)\right)$for each choice and $S_{i}=\sum_{j=1}^{N} w_{j} \cdot\left(\left(f_{j}^{*}-\right.\right.$
TABLE 7: Changing importance weight.

\begin{tabular}{cccc}
\hline$\Delta w$ & $\begin{array}{c}\text { Possibility to } \\
\text { happen }\end{array}$ & Amount of risk & Possibility to control \\
\hline+0.05 & 0.65 & 0.35 & 0.14 \\
-0.05 & 0.55 & 0.25 & 0.04 \\
\hline
\end{tabular}

$\left.\left.f_{i j}\right) /\left(f_{j}^{*}-f_{i}^{-}\right)\right)$for each criteria calculated, as given in Table 5, respectively.

According to Table 5, the calculated values of $S$ are given. Based on the results, the value of $S$ depends on the weight of the criteria. When criteria weight is greater than each other, value of $S$ is greater. Finally, $Q$ as the VIKOR index is calculated for each criterion, as given in Table 6 .

According to the indicators obtained from the VIKOR method, the option with the highest value is chosen as the most important option [30], based on the output obtained from Table 6, it can be concluded that amount of risk has the highest priority rank; therefore, it has been identified as the first challenge. Similarly, the possibility to happen and possibility to control in manufacturing firms were identified as the next challenges. 
TABLE 8: Changing value of $S$ and $Q$.

\begin{tabular}{lcccc}
\hline Index & \multirow{2}{*}{$\Delta w$} & & \multicolumn{2}{c}{ Criteria } \\
& & Possibility to happen & Amount of risk & Possibility to control \\
\hline$S$ & \multirow{2}{*}{+0.05} & 8.64 & 4.57 & 1.51 \\
$Q$ & \multirow{2}{*}{0.05} & 0.985 & 0.944 & 0.352 \\
\hline$S$ & & 7.31 & 3.27 & 0.43 \\
$Q$ & & 0.783 & 0.882 & 0.031 \\
\hline
\end{tabular}

4.1. Sensitivity Analysis. In this section, by changing the importance weight value to $\Delta w= \pm 0.05$, we examine the modified results. Table 7 provides the value of new weight according to $\Delta w=w_{\text {old }}-w_{\text {new }}= \pm 0.05$. Also, Table 8 provides the value changed for the new weights. Based on the calculated results, if the weight increases, the $S$ values will increase. Consequently, in such condition, the value of the VIKOR index $(Q)$ also increases.

\section{Managerial Insights}

According to the results, study findings can add valuable knowledge to managers. Based on the results, in addition to identifying the challenges facing small and medium industries in granting government subsidies, ranking and selection of important choices has been done. In addition to the valuable results of this study, there are limitations that include the following:

(i) In this study, a questionnaire was used to find the background; as a result, some people may refuse to provide a real answer and give an unreal answer.

(ii) This research has been done cross-sectionally. Because of this, it makes it difficult to draw conclusions about causality.

(iii) The large number of questions in the questionnaire led to the prolongation of its implementation time, which did not affect the accuracy of the participants' answers

\section{Conclusion}

Currently, industry faces many problems such as production expense that increases raw material expense, payments, and the price of energy transporter. Generally speaking, different sectors experience different effects, but virtually, all sectors will be affected. If a firm is not a big energy user, it may be affected by an energy user firm or the high payment of its human resource, as they need more money to work. The increased costs will reduce profit margins, unless permission is given to raise prices in relation to increased costs. The results showed that the most important challenge small and medium enterprises face is exchange rate volatility after the targeted subsidy and lack of space in between the challenges of innovation and creativity. Consider that removing subsidies and later increased price of energy transporter causes increasing production expense and decreases margin profit of small and medium firms.

(i) Using empty firm's production capacity more (ii) Facilitating investors' access to finance resources based on rates approved by the central bank and central bank supervision on the cost of financing in various alternatives

(iii) Reducing tariffs on raw materials and intermediate irreplaceable internal production requirements

(iv) Prioritizing the payment of credit facilities for the purchase of new technologies

(v) Reducing transportation costs by optimizing transportation capacity

(vi) Changes in the product portfolio and consumption patterns

(vii) Raising the level of continuing education and new skills and proficiency of workforce

(viii) Shortening the supply chain

(ix) Promotion and improvement of quality management systems standards

(x) Reducing duplication and reducing tails

(xi) Reducing of production cycles/increasing the volume of production of goods and services

(xii) Reducing sleep time of machinery and equipment

\section{Data Availability}

No data were used to support this study.

\section{Conflicts of Interest}

The authors declare that they have no conflicts of interest.

\section{References}

[1] M. Shayeghi, The Role of Small and Medium Enterprises in Developing Countries Export, Aria Publications, Tehran, Iran, 2007.

[2] M. Asgari, How Competitive the Small and Medium Enterprises to Develop Exports, Institute of Business Studies and Research, Tehran, Iran, 2008.

[3] E. Aykan, S. Aksoylu, and E. Sönmez, "Effects of support programs on corporate strategies of small and medium-sized enterprises," Procedia-Social and Behavioral Sciences, vol. 99, no. 99, pp. 938-946, 2013.

[4] B. Amin, A. Ali, and S. M. Smith, "Address the obstacles to the development of small and medium enterprises and provide a framework to support these firms," Enterprises and Society, vol. 138, Article ID 34, 2011.

[5] A. Ghasemi and M. Scientific Moghaddam, "Enhancing the competitiveness of small and medium enterprises, power their 
financing with an emphasis on cluster development approach," And Economic Policy, vol. 94, pp. 90-81, 2009.

[6] M. Nateghi and Qalati, "The need for small and medium enterprises clustering," Monthly Tact, vol. 173, pp. 25-38, 2006.

[7] R. K. Lynn, Communicating Sustainability for the Green Economy, E. Gurel-Atay, Ed., M.E. Sharpe, New York, NY, USA, 2014.

[8] D. Finn, Our Uncertain Future: Can Good Planning Create Sustainable Communities?, University of Illinois, ChampaignUrbana, IL, USA, 2009.

[9] U. Grober, Deep Roots-A Conceptual History of "Sustainable Development" (Nachhaltigkeit), Wissenschaftszentrum Berlin für Sozialforschung, Berlin, Germany, 2007.

[10] C. Liu, W. Huang, and C. Yang, "The evolutionary dynamics of China's electric vehicle industry-taxes vs. subsidies," Computers \& Industrial Engineering, vol. 113, pp. 103-122, 2017.

[11] R. Kumar, R. R. Kumar, P. J. Stauvermann, and J. Chakradhar, "The effectiveness of fisheries subsidies as a trade policy tool to achieving sustainable development goals at the WTO," Marine Policy, vol. 100, pp. 132-140, 2019.

[12] H. Moghaddam and F. Wirl, "Determinants of oil price subsidies in oil and gas exporting countries," Energy Policy, vol. 122, pp. 409-420, 2018.

[13] L. Grilli and S. Murtinu, "Selective subsidies, entrepreneurial founders' human capital, and access to R\&D alliances," Research Policy, vol. 47, no. 10, pp. 1945-1963, 2018.

[14] Z. Thorne and L. Hughes, "Evaluating the effectiveness of electric vehicle subsidies in Canada," Procedia Computer Science, vol. 155, pp. 519-526, 2019.

[15] S. A. Solarin, "Towards sustainable development in developing countries: aggregate and disaggregate analysis of energy intensity and the role of fossil fuel subsidies," Sustainable Production and Consumption, vol. 24, no. 24, pp. 254-265, 2020.

[16] L. Zhang, R. Long, Z. Huang, W. Li, and J. Wei, "Evolutionary game analysis on the implementation of subsidy policy for sustainable transportation development," Journal of Cleaner Production, vol. 10, no. 267, pp. 122-159, 2020.

[17] Y. Shi, Y. Deng, G. Wang, and J. Xu, "Stackelberg equilibriumbased eco-economic approach for sustainable development of kitchen waste disposal with subsidy policy: a case study from China," Energy, vol. 1, no. 196, pp. 117-171, 2020.

[18] Y. C. Tsao, V. V. Thanh, Y. Y. Chang, and H. H. Wei, "COVID-19: government subsidy models for sustainable energy supply with disruption risks," Renewable and Sustainable Energy Reviews, vol. 1, no. 150, pp. 111-125, 2021.

[19] Y. Song, J. M. Sahut, Z. Zhang, Y. Tian, and L. Hikkerova, "The effects of government subsidies on the sustainable innovation of university-industry collaboration," Technological Forecasting and Social Change, vol. 174, Article ID 121233, 2022.

[20] H. A. Izadyar and S. Pride Azam, Fuzzy Multi-Criteria Decision-Making, pp. 225-227, Publishing Inscription Gale, Farmington Hills, MI, USA, 2014.

[21] S. Woodhouse, B. Burney, and K. Coste, "To err is human: improving patient safety through failure mode and effect analysis," Clinical Leadership \& Management Review: The Journal of CLMA, vol. 18, no. 1, pp. 32-36, 2004.

[22] R. J. Cody, “Anticipating risk for human subjects participating in clinical research: application of Failure Mode and Effects Analysis," Cancer Investigation, vol. 24, no. 2, pp. 209-214, 2006.
[23] E. Ardeshir-Larijani, S. J. Gay, and R. Nagarajan, "Equivalence checking of quantum protocols," in Proceedings of the International Conference on Tools and Algorithms for the Construction and Analysis of Systems, pp. 478-492, Rome, Italy, March 2013.

[24] S. Opricovic and G.-H. Tzeng, "Extended VIKOR method in comparison with outranking methods," European Journal of Operational Research, vol. 178, no. 2, pp. 514-529, 2007.

[25] M. Bahraminasab and A. Jahan, "Material selection for femoral component of total knee replacement using comprehensive VIKOR," Materials \& Design, vol. 32, no. 8-9, pp. 4471-4477, 2011.

[26] I. A. Dicle and U. Dicle, "Effects of government export policies on Turkish export trading companies," International Marketing Review, vol. 9, no. 3, pp. 62-76, 1992.

[27] M. C. Cant, J. A. Wiid, and S. M. Kallier, "Product strategy: factors that influence product strategy decisions of SMEs in South Africa," Journal of Applied Business Research, vol. 31, no. 2, pp. 621-630, 2015.

[28] C. Y.-Y. Lin and J. Zhang, "Changing structures of SME networks: lessons from the publishing industry in taiwan," Long Range Planning, vol. 38, no. 2, pp. 145-162, 2005.

[29] D. B. Zoogah, M. W. Peng, and H. Woldu, "Institutions, resources, and organizational effectiveness in Africa," Academy of Management Perspectives, vol. 29, no. 1, pp. 7-31, 2015.

[30] E. Asgharizadeh and F. Valipoor, "Degree performance evaluation methods and techniques managers to decide VIKOR (Case Study Agricultural Engineering Research Institute)," Industrial Management Studies, vol. 23, pp. 21-48, 2011. 